\title{
Evaluation of elite British cyclists: the role of the squad medical
}

\author{
Michael J Callaghan, Christopher Jarvis
}

\begin{abstract}
Objective-To describe and report results from the procedures and protocols used by the British Cycling Federation during the squad medicals of its elite cyclists.

Methods-Screening of over 500 elite riders has been done by doctors, dentists, physiotherapists, opticians, and dietitians since 1990. A questionnaire provided additional information on musculoskeletal problems.

Results-523 riders have been examined and $92(17.5 \%)$ have been referred for further assessment or treatment. Most of these riders were sent either to their own general practitioner or to the British Olympic Medical Centre. The questionnaire was completed by $81 \%$ of riders. Low back pain was the most common problem that riders encountered $(60 \%)$, and knee pain the second most common (33\%). Four riders failed the eye examination, and a further 11 were classed as borderline. Twenty one per cent of riders undergoing dental examination needed further dental treatment

Conclusions-The squad medical is an important and useful strategy for evaluating elite British cyclists. It shows that a structured system can help early diagnosis and treatment to provide injury-free cyclists at the start of a competitive season. The results from the questionnaire confirm previously unsubstantiated opinions about the incidence of musculoskeletal injuries in cyclists.

(Br f Sports Med 1996;30:349-353)
\end{abstract}

British Cycling

Federation, Velodrome

Physiotherapy and

Sports Injuries Clinic, National Cycling Centre, Manchester

M J Callaghan, honorary physiotherapist

British Cycling Federation, The Surgery, Boscastle, Cornwall

C Jarvis, honorary medical officer

Correspondence to: Michael J Callaghan, Department of

Physiotherapy, Royal Liverpool University Hospitals, Prescott St Liverpool L7 8XP, United Kingdom.

Accepted for publication 9 July 1996

Key terms: cycling; sports injuries; medical screening

Medical screening of elite athletes can be a costly and logistically difficult problem, particularly in individual sports and those which involve a large amount of solo training, since competitors are not assembled as squads in the winter. Athletes in this situation can spend the non-competitive months in little contact with either coaching or medical staff.

Consequently, sportsmen and women can develop problems which may only come to light at the start of the competitive season and which may result in a loss of important winter background training. Ideally, diagnosis of an injury or illness should be made in the "off season" when treatment can be instigated. Personal communication with other medical staff suggests that there are other Olympic sports where recognition of an injury occurs only when a competitor presents at a championships. In order to address some of these problems the British Cycling Federation (BCF) set up a system for medical screening of international elite riders in 1986. This now takes place in winter and is also used as a planning session for both riders and officials. The aims of the winter squad medical were to obtain early diagnosis of injury and monitoring of "known" problems (for example, asthma), to diagnose silent pathologies such as anaemia or heart murmurs, to confirm the legality of rider's medication, to give dietary advice, and to allow the cyclists to undergo dental, physiotherapy, and ophthalmic assessment.

In this paper we outline the protocols and procedures involved and presents the results from the riders during this time.

\section{Methods}

OFFICIALS

Since 1990 the squad medical has used the services of the following practitioners: four doctors, one physiotherapist, one dentist, one dietitian, one optician, and one nurse. All these practitioners have the advantage of having been past participants in cycling in some form, and are familiar with examination and treatment of cyclists over a number of years. Furthermore, the coaches (track, road, mountain bike) and exercise physiologists are also present for the entire weekend. This makes for excellent liaison between cyclist, coach, medical staff, scientist, and other officials of the BCF.

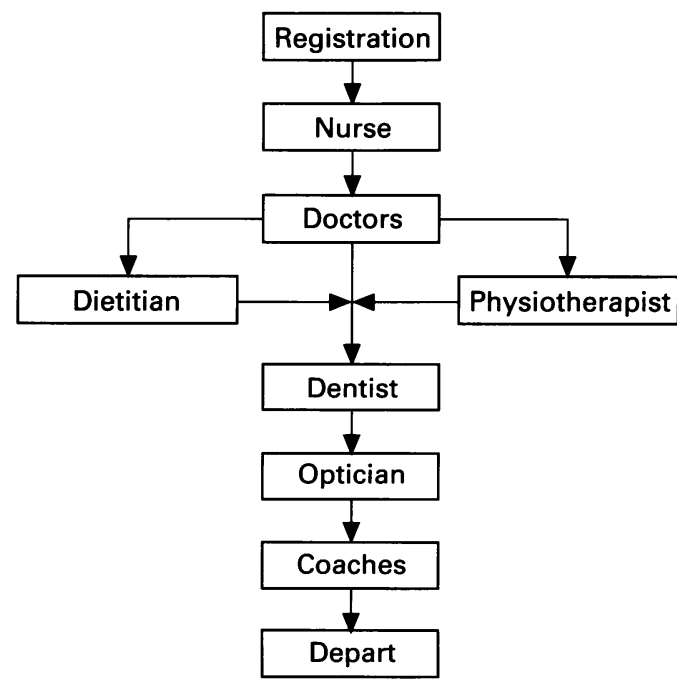

Figure 1 Appointment flow. 
Table 1 Numbers seen at BCF squad medicals and percentage referred for further investigation

\begin{tabular}{lcl}
\hline Year & Number of riders & Number referred (\%) \\
\hline 1990 & 87 & 14 \\
1991 & 91 & 16 \\
1992 & 84 & 13 \\
1993 & 89 & 17 \\
1994 & 85 & 19 \\
1995 & 87 & 20 \\
Total & 523 & 17.5 \\
\hline
\end{tabular}

Table 2 Diagnosis and destination of referrals (1990-1995), total $=92$

\begin{tabular}{lllll}
\hline Diagnosis & BOMC & Consultant & GP & Other \\
\hline Cardiovascular & 4 & & 9 & \\
Low back pain & 6 & & 2 & \\
ENT & 1 & 9 & \\
Respiratory/asthma & 7 & 2 & \\
$\begin{array}{l}\text { Anaemia/ } \\
\quad \text { haematology }\end{array}$ & & 6 & \\
$\begin{array}{l}\text { Dysmenorrhoea } \\
\text { Lower limb }\end{array}$ & 1 & & 4 & \\
Upper limb & 4 & 1 & 5 & 2 \\
$\begin{array}{l}\text { Dermatology } \\
\text { Neurology }\end{array}$ & 1 & 1 & 2 & \\
$\begin{array}{l}\text { Urology } \\
\text { Osteoporosis risk }\end{array}$ & 1 & 1 & 4 & \\
Groin & 1 & & 1 & \\
Others & 7 & & 2 & 1 \\
\hline
\end{tabular}

BOMC, British Olympic Medical Centre.

Table 3 Numbers referred after dental examination

\begin{tabular}{lll}
\hline Year & $\begin{array}{l}\text { Number of riders } \\
\text { examined }\end{array}$ & $\begin{array}{l}\text { Percentage and number of } \\
\text { riders needing further } \\
\text { treatment }\end{array}$ \\
\hline 1990 & 83 & $25(21)$ \\
1991 & 89 & $18(16)$ \\
1992 & 59 & $39(23)$ \\
1993 & 77 & $26(20)$ \\
1994 & 80 & $18(14)$ \\
1995 & 79 & $10(8)$ \\
Total & 467 & $21(102)$ \\
\hline
\end{tabular}

FACILITIES

The venue is a midland Hospital in England, which has easy aeroplane, train, and road access. The medical facilities are in the outpatient suite and include magnetic resonance (MR) scanning, $x$ rays, blood analysis, urinalysis, and consulting/examination rooms for all medical personnel and coaching staff. Administrative facilities are also available for rapid processing of referral letters to the riders' own general practitioners, consultants, the British Olympic Medical Centre (BOMC), and other medical personnel.

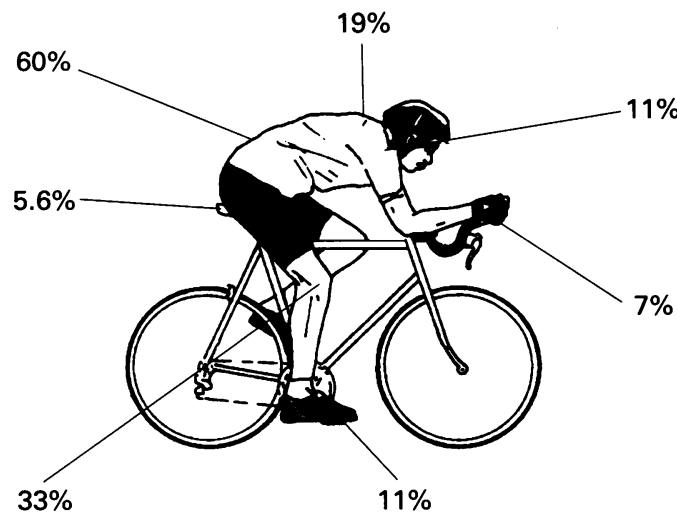

Figure 2 Relative frequency of injuries in various areas.
Table 4 Diagnosis and number of referrals to physiotherapist

\begin{tabular}{llll}
\hline Diagnosis & 1993 & 1994 & 1995 \\
\hline Patellofemoral pain & 2 & & \\
Low back pain & 2 & 5 & 4 \\
Neck pain & 1 & & \\
Upper limb & 2 & 2 & 4 \\
Lower limb & 3 & 2 & 6 \\
Groin pain & 1 & 1 & 1 \\
Advice & 1 & 7 & 1 \\
\hline
\end{tabular}

Table 5 Reasons for specific dietary referral

\begin{tabular}{lll}
\hline & 1993 & 1995 \\
\hline Iron, folate, B-12 advice & 3 & 2 \\
Weight control & 9 & 2 \\
Allergies; diet exclusion & & 1 \\
Dental decay advice & & 1 \\
Fluid intake advice & 3 & \\
Vitamin supplements & 1 & \\
\hline
\end{tabular}

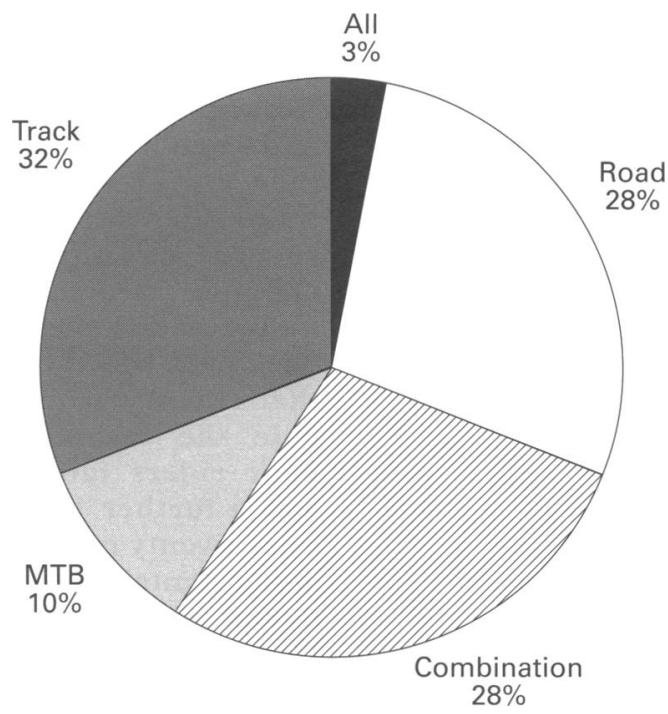

Figure 3 Source of knee injuries. $M T B=$ mountain bike; All = all disciplines.

\section{PROCEDURES}

All cyclists are seen initially by the nurse who has a "practice manager role" for the weekend and coordinates the flow of appointments (fig 1). All riders undergo a full medical examination by one of the medical officers, preceded by a full blood count and (if necessary) blood grouping. The riders can then be referred directly to the physiotherapist for further musculoskeletal assessment or (increasingly) prophylactic advice. Referral can also take place at this stage to the dietitian for general discussion or advice for a specific problem. The riders then have a full dental examination and in 1993 also had vision screening by an optician. All riders have to be interviewed by the national coach or specialist coach to plan the year's events and training.

In 1995 , as part of its cardiomyopathy screening programme, the Department of Cardiology at St George's Hospital, London, screened 82 riders by questionnaire, electrocardiogram, and echocardiogram.

INCIDENCE OF INJURY

In 1995,71 of the 87 international squad members were interviewed by questionnaire to 


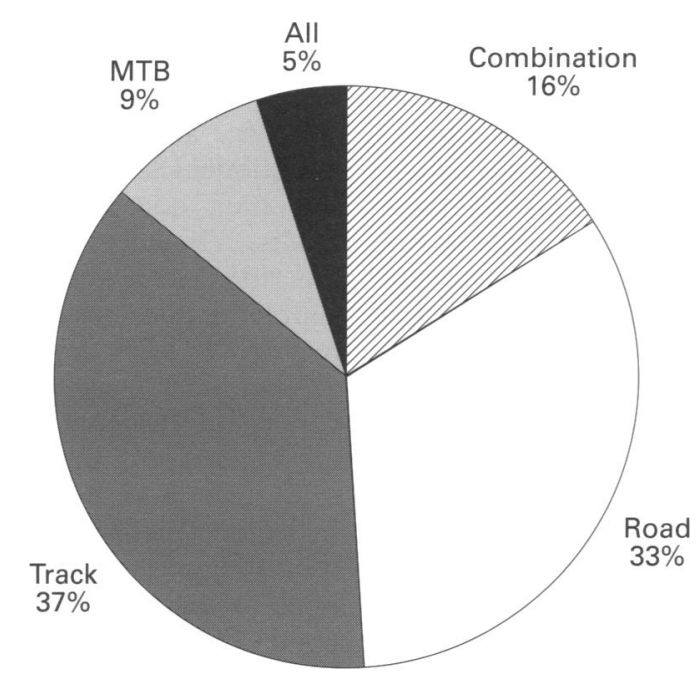

Figure 4 Source of low back injuries. $M T B=$ mountain bike; $A l l=$ all disciplines.

ascertain the incidence of traumatic and atraumatic injuries, past and present, in elite British riders. There have been few studies into the epidemiology and incidence of cycling injuries and to our knowledge none has been conducted on a comparable group of elite riders. Weiss ${ }^{1}$ collected data from 113 amateur riders with an average age of 40 years during a 500 mile bicycle ride in the USA. This showed that riders sustained mainly atraumatic injuries. Most work on cyclists' injuries is based on anecdotal evidence. ${ }^{2}$ It has been calculated that cycling injuries account for 500000 visits to accident and emergency rooms in the USA. ${ }^{3}$ One accident and emergency department in the United Kingdom reported 382 admissions after cycling accident in a six month period. ${ }^{4}$

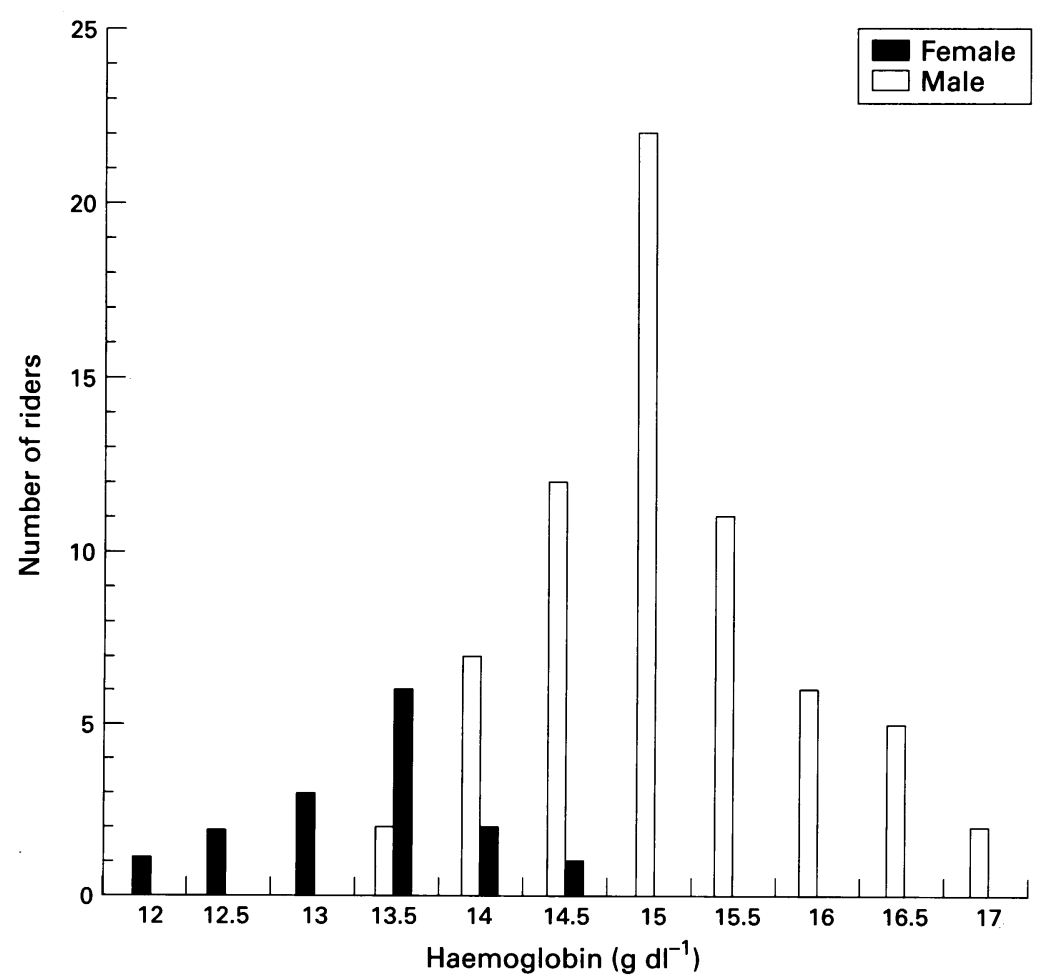

Figure 5 Haemoglobin values in 83 riders.

\section{Results}

MEDICAL EXAMINATIONS

In each year, over a two day period, an average of 87 riders have been seen (tables 1 and 2). There is a male:female ratio of $5: 1$. This covers all squads (track, road, mountain bike) from junior to full international level. Since 1993 this has also included the top British professionals.

Table 3 shows the number of riders seen for dental examination and those who required further dental referral.

The numbers and breakdown of referrals to the physiotherapist are given in table 4 , and information concerning the dietetic referrals in table 5 . In addition to specific advice there was general discussion with riders on the subjects of carbohydrate intake, vegetarian diets, protein requirements, race feeding strategies, and sports and energy drinks. The results of the vision screening programme revealed that out of 74 riders examined in 1993, four failed the test and full eye examination was recommended for these. Furthermore, 11 riders were classed as being borderline in the pass/fail criteria and it was suggested that they have a full eye examination.

\section{QUESTIONNAIRE}

The questionnaire collected data from 71 riders $(81 \%)$. This requested information regarding the incidence of low back pain, sciatica, and related neurological symptoms. They were also asked about the duration of the problem, its cause, and how it affected training. In addition, they were asked about other musculoskeletal problems throughout the rest of the body. For simplicity of terminology the cyclists were not asked to differentiate between patellofemoral pain and other forms of knee pain. Results were compiled using the Microsoft Access database. The areas of injury are given as percentages in fig 2 . Further breakdown of the replies concerning the two most common problem areas (that is, knee and low back) are shown in fig 3 and 4 . Figure 5 shows the results of haemoglobin levels taken from 83 riders $($ male $=67$; female $=15)$ in 1995 .

\section{Discussion}

MEDICAL EXAMINATION

The squad medical has given coaches, science, and medical support staff a unique opportunity to assess and advise nearly all the elite cyclists in Britain on a yearly basis. The tables of results show a considerable number of cyclists present with problems which need further referral.

The doctors referred an average of 18 riders each year to the riders' own general practitioners, or to the BOMC or a consultant for specialist advice (table 2). This enables the riders to be seen as quickly as possible for treatment after the medical has been completed. The presence of four doctors allows a consultation time of approximately 30 minutes for each cyclist. To maximise the value of the consultation there must be adequate time set aside to build relationships with newer squad members. This can facilitate the exploration of 
any issues raised by the rider and provide information on drug control issues. The role of the doctor must be defined within the particular context of the squad medical assessment. Primarily, the doctor is present to act on behalf of the BCF; he is not the rider's personal physician. Confusion about this has resulted in the past, with medical information occasionally being withheld from the examining doctor because a competitor believes that their fitness for a racing licence might be in doubt, or that their selection for a team could be prejudiced.

The cardiomyopathy screening programme, present for the first time in 1995, was in part research based, but also intended to increased awareness of hypertrophic cardiomyopathy (HOCM) within the cycling community. This is thought to be the commonest cause of sudden death in young endurance athletes, although the case against cardiac hypertrophy is far from established due to weak diagnostic criteria and frequent republication of a very small group of cases. ${ }^{5}$ Some measure of the physical condition of the elite cyclist examined can be derived from the fact that 18 of those examined $(26.1 \%)$ has resting heart rates of 40 beats $\mathrm{min}^{-1}$ or below. Of the 82 cyclists screened in this programme, one was shown to have an aortic valve anomaly justifying follow up investigation and antibiotic prophylaxis.

The types of problems discovered on history or during examination are usually relatively insignificant (table 2). Among the more significant discoveries have been asymptomatic cardiac murmurs, palpitations, and syncopal episodes requiring cardiac investigation, anaemia, and raised haemoglobin levels.

Increasing importance is necessarily being placed on athlete drug education and on the scrutiny of any medications or supplements being ingested by competitors. Clearly, the sooner this dialogue starts the better for all involved. The consultation with the doctor provides an opportunity to raise and explore the subject on a one to one basis.

Dental examination revealed that out of a total of 467 riders, $102(21 \%)$ needed further treatment. In 1992 three cyclists presented with problems that had already been identified in 1991 - the riders had failed to obtain the recommended treatment! It was also noticed that a small number of riders had dental phobia and avoided the free examination provided by the BCF. Consequently, some riders were never examined and their dental status remains unknown. The results from those undergoing examination confirm that all too frequently cyclists neglect even the most basic of health care. The authors have experience at Olympic and Commonwealth Games of elite cyclists presenting with acute dental problems that could have been prevented by proactive dental care.

The vision screening, although only available from one year, did allow a snapshot of the elite cyclists' eyesight status. It revealed that four riders actually failed the standard eye test. These riders were urged to visit their local optician for further assessment. This is an area of concern in cycling as in all cycling disciplines good vision is essential for safety. It is unlikely, however, that minor visual errors found in 11 riders will result in reduced performance.

Advice and further counselling from sports nutritionists has become invaluable after initial screening questions showed unusual dietary habits. The topics most frequently raised by our riders were vegetarianism, iron or vitamin supplementation, carbohydrate loading, and recently creatine supplementation.

The musculoskeletal assessment often becomes a three way consultation between physiotherapist, the referring doctor, and the rider, which is helpful in the diagnosis and treatment planning. We have elicited a very useful "cross pollination" education component to these examinations which provides a good example of the cooperation needed between physiotherapist and physician for the ultimate benefit of the rider. This has become evident with the number of riders referred for advice on stretching and other forms of prophylaxis. Where appropriate, the physiotherapist will contact facilities locally for the cyclist to have treatment.

\section{QUESTIONNAIRE}

The questionnaire confirmed the previously generally accepted (though anecdotal) beliefs that the two major musculoskeletal problems that cyclists encounter are knee pain and back pain. The results confirm the view of Mellion ${ }^{2}$ that back pain is an extremely common problem in cycling, and that of Holmes et al ${ }^{6}$ who considered knee pain to be the most common lower extremity overuse problem. Our incidence was higher $(33 \%)$ than that reported by Hannaford $e t a l,{ }^{7}$ in whose study knee injuries accounted for $25 \%$ of all reported injuries.

Interestingly, there was very little difference in the incidence of low back pain between the pure track riders $(32 \%, \mathrm{n}=14)$, the pure road riders $(28 \%, n=12)$, or the cyclists who combine both types of racing ("combination") $(28 \%, n=12)$. It has often been thought that the longer hours spent in the saddle by road riders may predispose them to more low back pain than others who have a shorter competition time. This questionnaire indicates that both road and track riders are more or less equally affected. Track riders spend less time in the saddle by the very nature of track events and have different anthropometry than other cycling disciplines. ${ }^{8}$ This, coupled with the emphasis on power and weight training in sprinters, for example, may explain the finding.

With regard to knee pain, the ratio between track and road riders were similar (track: $\mathrm{n}=9$, $37 \%$; road: $n=8,33 \%$; combination: $n=4$, $16 \%)$. It has been suggested that the higher gears pushed by road race cyclists and time trialists may make them prone to knee pain ${ }^{3}$ due, normally, to higher gears causing an increase in the patellofemoral joint reaction force. However, we found that track and road riders were equally affected by this problem.

\section{CONCLUSION}

In this paper we have presented data from six years of examining elite British cyclists in the 
context of the annual squad medical. The medical provides a unique opportunity for the medical personnel involved in British cycling to gather and examine these riders and also provides an excellent environment for liaison between riders, coaches, and medical staff. Of those examined since $1990,17.5 \%$ have been referred for further tests, chiefly at the BOMC or by the riders' own general practitioners. We believe that this is an important and useful event with a structured system in which early diagnosis can be achieved and treatment initiated at the earliest opportunity with the aim of providing injury and illness free cyclists at the start of the competitive season.

We are very grateful for the help and information from the following: Dr Ian Holtby, Dr Dave Edge, Dr Gary Williams, Dr
Chris Butler, Dr G. Brown, Dr R Goodfellow, Dr K Watson, Dr
E Gradwell, Mr Rob Smith RGN, Ms Anne O'Hare BDS, MSc, Mrs L Brown, Mr T Stahl FRCS, Professor W McKenna FRCP, Mr Doug Coombes BA, MCSP, Ms Sarah Clarke BSc (Hons), MBCO, Ms Justine Cotterill BSc, MMedSci. For organisation of the medicals-Mr Tony Yorke. For providing he facilities-Edgbaston Nuffield Hospital. For advice on Microsoft database-Mrs P Whitaker MCSP.

1 Weiss BD. Non traumatic injuries in amateur long distance bicyclists. Am $\mathcal{F}$ Sports Med 1985;13:187-92.

Mellion MB. Neck and back pain in bicycling. Clin Sports Med 1994;13:137-64

3 Mellion MB. Common cycling injuries, management and prevention. Sports Med 1991;11:52-70.

4 Ballham A, Absoud EM, Kotecha MB, Bodiwala GG. A study of bicycle accidents. Injury 1985;16:405-8.

5 Shepherd RJ. The athlete's heart: is big beautiful? Br 7 Sports Med 1996;30:5-10.

6 Holmes JC, Pruitt AL, Whalen NJ. Lower extremity overuse in bicycling. Clin Sports Med 1994;13:187-205.

7 Hannaford DR, Moran GT, Hlavac HF. Video analysis and treatment of overuse knee injury in cycling: a limited clinitreatment of overuse knee injury in cycling:

8 Foley JP, Bird SR, White JA. Anthropometric comparison of Foley JP, Bird SR, White JA. Anthropometric comparison of
cyclists from different events. Br f Sports Med 1989;23:30-3. 